Fata Nidaul Khasanah, S.Kom., M.Eng.

Sugeng Murdowo, S.T., S.Kom., M.Kom.

\title{
KIAT SUKSES MEMBUAT PUPUK ORGANIK CAIR DARI HASIL PENGOLAHAN SAMPAH DAUN KERING
}

\section{SAMPAI PROSES}
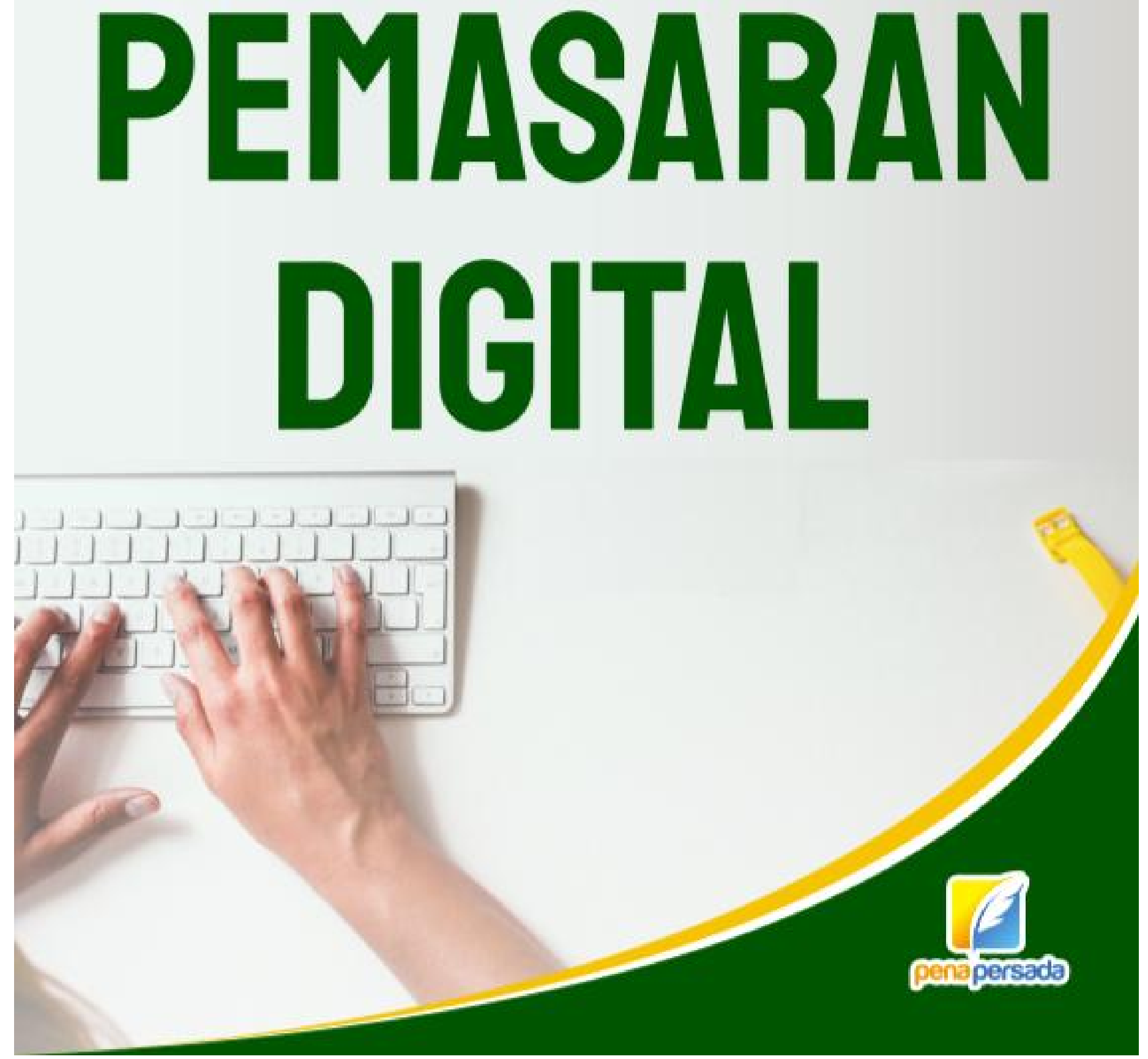
KIAT SUKSES MEMBUAT PUPUK ORGANIK CAIR DARI HASIL PENGOLAHAN SAMPAH DAUN KERING SAMPAI PROSES PEMASARAN DIGITAL

FATA NIDAUL KHASANAH, S.KOM., M.ENG.

SUGENG MURDOWO, S.T., S.KOM., M.KOM.

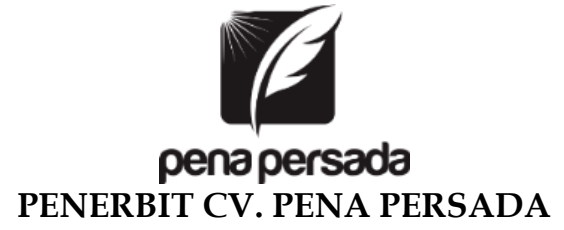




\title{
KIAT SUKSES MEMBUAT PUPUK ORGANIK CAIR DARI HASIL PENGOLAHAN SAMPAH DAUN KERING SAMPAI PROSES PEMASARAN DIGITAL
}

\author{
Penulis: \\ FATA NIDAUL KHASANAH, S.KOM., M.ENG. \\ SUGENG MURDOWO, S.T., S.KOM., M.KOM.
}

ISBN :

Design Cover :

Arsyie Kania Rakhma

Layout :

Mutolib

Penerbit CV. Pena Persada

Redaksi :

Jl. Gerilya No. 292 Purwokerto Selatan, Kab. Banyumas

Jawa Tengah

Email : penerbit.penapersada@gmail.com

Website : penapersada.com Phone : (0281) 7771388

\section{Anggota IKAPI}

All right reserved

Cetakan pertama : 2021

Hak Cipta dilindungi oleh undang-undang. Dilarang memperbanyak karya tulis ini dalam bentuk apapun tanpa izin penerbit 


\section{KATA PENGANTAR}

Segala puji penulis panjatkan kehadirat Allah SWT atas segala rahmat taufiq dan hidayahNya, sehingga penulis dapat menyelesaikan penyusuna buku ini.

Tak lupa, sholawat serta salam penulis ucapkan kepada junjungan Nabi Muhammad SAW.

Buku pertama ini penulis dedikasikan kepada kedua orang tua penulis H. Saebani, S.Ag., M.SI. dan Hj. Dra. Dwi Wahyuni atas segala dukungan dan doa yang tak henti selalu dipanjatkan untuk penulis. Tak lupa penulis juga ucapkan terima kasih kepada suami, anak-anak, keluarga, sahabat dan rekan dosen yang secara tidak langsung turut serta dalam mendukung proses penyusunan Buku Kiat Sukses Membuat Pupuk Organik Cair Dari Hasil Pengolahan Sampah Daun Kering Sampai Proses Pemasaran Digital.

Buku ini merupakan hasil penelitian yang telah dilakukan oleh penulis berisikan petunjuk teknis terkait dengan proses pengolahan pupuk, penggunaan dan perawatan mesin serta pemasaran hasil olahan pupuk secara digital.

Terdapat tiga bagian utama pada buku ini, yaitu penggunaan mesin pencacah sampah organik dan mesin penggiling sampah organik, proses pengolahan pupuk dan perawatan mesin mesin pencacah sampah organik dan mesin penggiling sampah organik.

Penulis menyadari bahwa penulisan buku referensi ini masih terdapat beberapa kekurangan, untuk itu saran demi perbaikan sangat dibutuhkan.

Sekali lagi, terima kasih penulis sampaikan kepada semua pihak yang telah membantu dalam proses penyusunan buku referensi.

Semoga dari buku ini dapat memberikan manfaat bagi para pembaca dan memberikan keberkahan.

Penulis 


\section{DAFTAR ISI}

KATA PENGANTAR ........................................................................ii

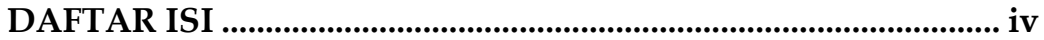

DAFTAR GAMBAR ..............................................................................

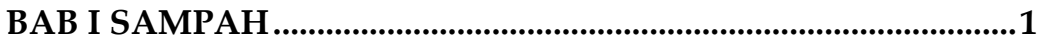

BAB II PUPUK ………...........................................................................

BAB III PUPUK KOMPOS CAIR ...............................................4

BAB IV PENGOLAHAN PUPUK KOMPOS CAIR ...........................6

A. Persiapan Pembuatan......................................................... 6

B. Pembuatan Pupuk Organik Cair ..................................... 10

BAB V PENGGUNAAN MESIN PENCACAH DAN MESIN

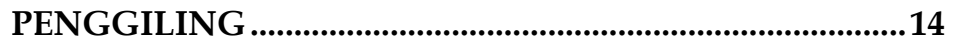

A. Mesin Pencacah ..................................................................... 14

B. Mesin Penggiling ……………….................................... 18

BAB VI PERAWATAN MESIN PENCACAH DAN MESIN

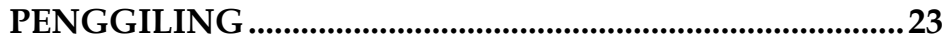

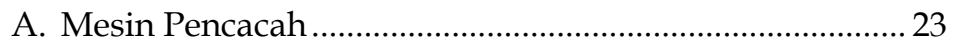

B. Mesin Penggiling .............................................................. 24

BAB VII PENGEMASAN DAN PEMASARAN ……......................26

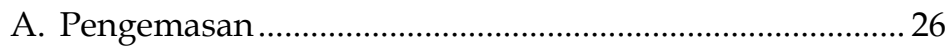

B. Pemasaran .................................................................... 27

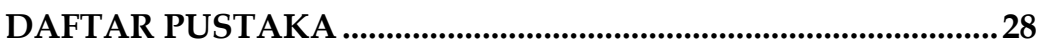




\section{DAFTAR GAMBAR}

Gambar 1. Sifat Sampah ....................................................................... 1

Gambar 2 Contoh Sifat Sampah ........................................................ 2

Gambar 3. Sumber-Sumber Sampah .................................................2

Gambar 4. Komponen Tong Komposter .......................................... 7

Gambar 5. EM4 ............................................................................9

Gambar 6. Pupuk Organik Cair ....................................................12

Gambar 7. Pupuk Organik Padat....................................................12

Gambar 8. Corong Mesin Pencacah...............................................15

Gambar 9. Pisau Pencacah .................................................................15

Gambar 10. Motor Listrik..................................................................16

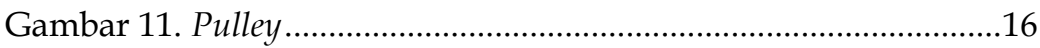

Gambar 12. Belt ......................................................................................17

Gambar 13. Mesin Pencacah Daun Kering .....................................17

Gambar 14. Gearbox ......................................................................19

Gambar 15. Motor Listrik...............................................................19

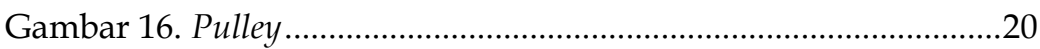

Gambar 17. Belt .....................................................................................20

Gambar 18. Mesin Mixer Kompos ....................................................22 
KIAT SUKSES MEMBUAT PUPUK ORGANIK CAIR DARI HASIL PENGOLAHAN SAMPAH DAUN KERING SAMPAI PROSES PEMASARAN DIGITAL 


\section{BAB I \\ SAMPAH}

Sampah merupakan material sisa yang terbuang atau dibuang dari aktivitas manusia maupun proses alam yang belum memiliki nilai ekonomis [Nugroho, 2018].

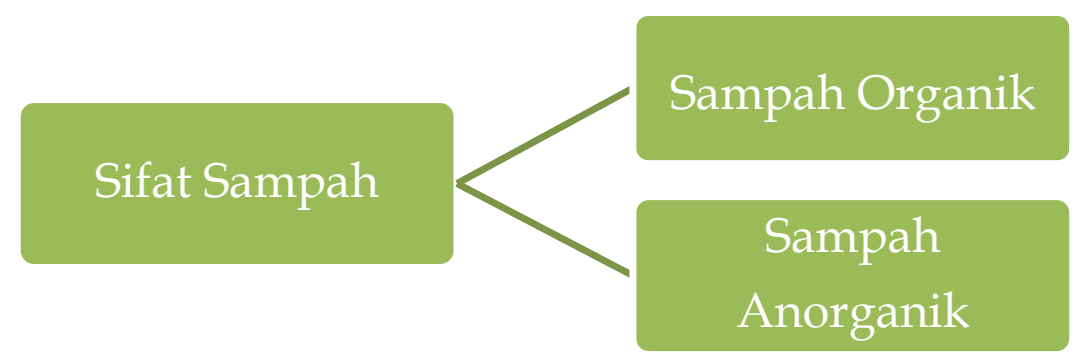

\section{Gambar 1. Sifat Sampah}

Berdasarkan sifatnya sampah dibedakan menjadi dua jenis, yaitu sampah organik dan sampah anorganik.

Sampah organik merupakan jenis sampah yang mudah membusuk, seperti sisa makanan, daun kering, sisa sayuran dan lainnya [Adiyanta, 2015]. Sampah organik terbagi menjadi dua jenis, yaitu sampah organik basah dan sampah organik kering. Sampah organik basah merupakan jenis sampah organik yang memiliki kandungan air cukup tinggi, seperti kulit buah dan sayuran. sampah organik kering merupakan jenis sampah organik yang memiliki kandungan air sedikit, seperti ranting pohon dan daun-daun kering. Sampah organik masih dapat digunakan kembali apabila dapat dikelola dengan prosedur yang benar. Sampah organik dapat mengalami pelapukan atau dekomposisi dan terurai menjadi bahan yang lebih kecil dan tidak berbau. Kompos merupakan hasil pelapukan sampah organik dimana proses pelapukannya dipercepat oleh bantuan manusia [Nugroho, 2018]. 
Sampah anorganik merupakan jenis sampah yang tidak mudah membusuk, seperti plastik, kaca, kayu dan lain sebagainya [Adiyanta, 2015]. Sampah ini dapat dijadikan sebagai sampah yang dapat laku untuk dijual atau memiliki nilai komerisil yang telah diubah menjadi bentuk lain, contohnya plastik wadah pembungkus makanan, botol, gelas dan lain sebagainya.

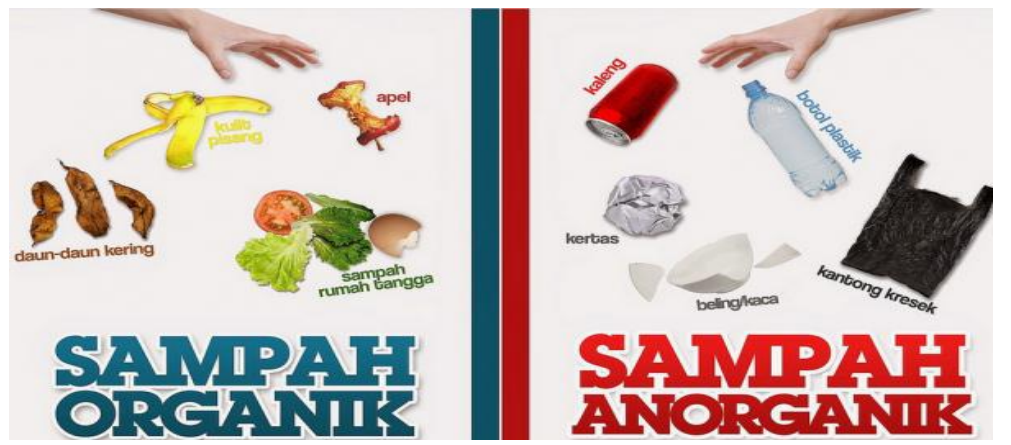

Gambar 2 Contoh Sifat Sampah

Sumber: https:/ /www.bulelengkab.go.id

Berdasarkan sumber-sumber sampah berasal dari sampah pemukiman, sampah pertanian dan perkebunan, sampah industri, sampah sisa konstruksi bangunan, sampah sekolah dan perkantoran, sampah pasar dan sampah khusus.

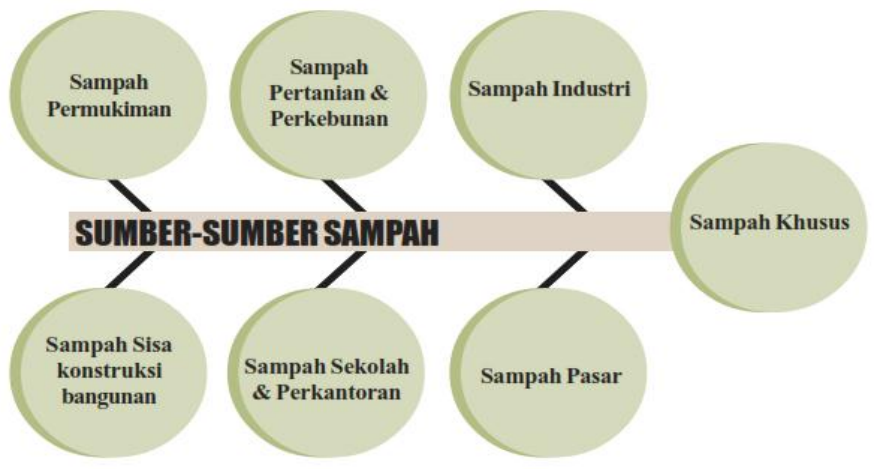

Gambar 3. Sumber-Sumber Sampah

Sumber: https://nusataniterpadu.files.wordpress.com 


\section{BAB II PUPUK}

Pupuk merupakan bahan yang ditambhakan ke dalam tanah yang nantinya dapat mempengaruhi pertumbuhan tanaman yang berasal unsur-unsur esensial yang dihasilkan [Hadisuwto, 2007].

Tujuan pemberian pupuk diantaranya untuk memperbaiki sifat fisis, sifat kimia dan sifat biologi pada tanah. Pemberian pupuk diharapkan agar tanaman dapat tumbuh, berkembang sesuai dengan yang diharapkan.

Berdasarkan sumber bahan pupuk dibedakan menjadi dua, yaitu pupuk organik atau alami dan pupuk kimia atau buatan.

Pupuk organik merupakan pupuk yang terbuat dari sisasisa metabolisme baik dari hewan maupun tumbuhan. Pupuk organik mengandung banyak bahan organik dibandingkan kadar haranya. Sumber bahan organik dapat berupa kompos, pupuk hijau, pupuk kandang, sisa panen dan limbah ternak [Nugroho, 2018].

Pupuk kimia merupakan pupuk yang dibuat secara kimia atau yang dikenal dengan pupuk buatan. Pupuk kimia dibedakan menjadi pupuk kimia tunggal dan pupuk kimia majemuk. Pupuk kimia tunggal merupakan pupuk kimia yang memiliki satu macam unsur hara, sedang kan pupuk kimia majemuk merupakan pupuk kimia yang memiliki kandungan hara lengkap yang merupakan pencampuran unsur hara dari pupuk kimia tunggal disesuaikan dengan kebutuhan.

Secara fisik pupuk dibedakan menjadi dua jenis, yaitu pupuk padat dan pupuk cair. Pupuk padat biasa diaplikasikan ke tanah/media tanam. Pupuk padat yang dipasarkan baisanya berupa remahan, butiran ataupun kristal. Pupuk cair diberikan ke tanaman dengan cara disemprotkan ke tubuh tanama. Pupuk cair yang dipasarkan biasanya berbentuk cairan atau konsentrat. 


\section{BAB III \\ PUPUK KOMPOS CAIR}

Kompos merupakan sisa hasil bahan organik yang berasal dari tanaman, hewan dan limbah organik yang telah mengalami proses dekomposisi atau fermentasi. Jenis tanaman yang biasa digunakan untuk kompos diantaranya jerami, sekam padi, sayuran yang busuk, daun kering dan sabut kelapa. Sedangkan jenis ternak yang dapat dijadikan untuk kompos diantaranya kotoran ternak, urin dan pakan ternak yang terbuang [Nugroho, 2018].

Pengomposan merupakan proses dimana bahan organik mengalami penguraian secara biologis, khususnya oleh mikroba yang memanfaatkan bahan organik sebagai sumber energi.

Membuat kompos adalah mengatur dan mengontrol proses alami agar kompos dapat terbentuk lebih cepat. Proses pembuatan pupuk perlu memperhatikan campuran bahan yang seimbang baik pemberian air yang cukup, pengaturan aerasi dan penambahan aktivator pengomposan.

Teknologi pengomposan sampah dapat dilakukan secara aerobik dan anaerobik baik dengan atau tanpa menggunakan aktivator. Pengomposan secara aerobik paling banyak digunakan karena mudah dan murah untuk dilakukan serta tidak membutuhkan proses pengontrolan yang terlalu sulit. Dekomposisi bahan dilakukan oleh mikroorganisme itu sendiri dengan bantuan udara. Sedangkan pengomposan secara anaerobik dilakukan dengan memanfaatkan mikroorganisme yang tidak membutuhkan udara dalam mendegradasi bahan organik.

Pupuk kompos cair adalah ekstrak dari hasil pembusukan bahan-bahan organik. Dari hasil pembusukan bahan organik seperti sisa tanaman maupun kotoran hewan dapat diambil nutrisi atau unsur esensial yang terkandung dalam bahan organik tersebut. Selain mengambil nutrisi juga dapat memanfaatkan mikroorganisme, bakteri, fungi ataupun yang lainnya yang terdapat dalam bahan organik. Pupuk organik cair apabila 
dicampur dengan pupuk organik padat dapat mengaktifkan unsur hara yang terdapat dalam pupuk organik padat.

Pupuk kompos cair dapat diklasifikasikan dalam beberapa jenis, diantaranya pupuk kandang cair, pupuk cair limbah organik, effective microorganisme (EM) dan biogas.

Pupuk kandang cair merupakan pupuk kandang yang berbentuk cair berasal dari kotoran hewan yang masih segar seperti urin yang dilarutkan dengan air berdasarkan perbandingan tertentu. Pupuk cair limbah organik mengandung unsur hara khususnya NPK dan organik lainnya. Pupuk effective microorganisme adalah pupuk organik yang dibuat melalui proses fermentasi menggunakan bakteri (microorganisme). Biogas merupakan gas yang dihasilkan oleh aktivitas anaerobik atau fermentasi dari bahan organik, seperti kotoran manusi, kotoran hewan, limbah rumah tangga. Kandungan utama dari biogas adalah metana dan karbon dioksida. 


\section{BAB IV \\ PENGOLAHAN PUPUK KOMPOS CAIR}

\section{A. Persiapan Pembuatan}

\section{Komposter}

Komposter merupakan alat yang digunakan untuk membantu kerja bakteri pengurai (decomposer) aneka material organik berupa sampah dan limbah menjadi bentuk baru.

Komposter yang digunakan terbuat dari tong plastik yang dimodifikasi. Komposter memiliki instalasi untuk sirkulasi udara di dalamnya sehingga dapat membantu proses pengomposan aerob dan mempercepat proses penguraian sampah. Selain itu, komposter juga mampu menjaga kelembapan dan suhu sehingga bakteri dan jasad renik dapat bekerja mengurai bahan organik secara optimal. Komposter juga memungkinkan aliran lindi terpisah dari material padat sehingga memudahkan untuk mendapatkan pupuk cair [Cisanti, 2018].

Komponen yang terdapat pada tong komposter meliputi pipa PVC, saringan, kran air. Pipa PVC dilubangi untuk mengatur sirkulasi udara di dalam tong. Saringan berfungsi sebagai pemisah cairan yang berasal dari material padat, sehingga saringan ini nantinya memiliki fungsi sebagai pemisah untuk mendapatkan pupuk padat dan pupuk cair. Kran air berfungsi untuk mengambil hasil pupuk cair yang dihasilkan. 


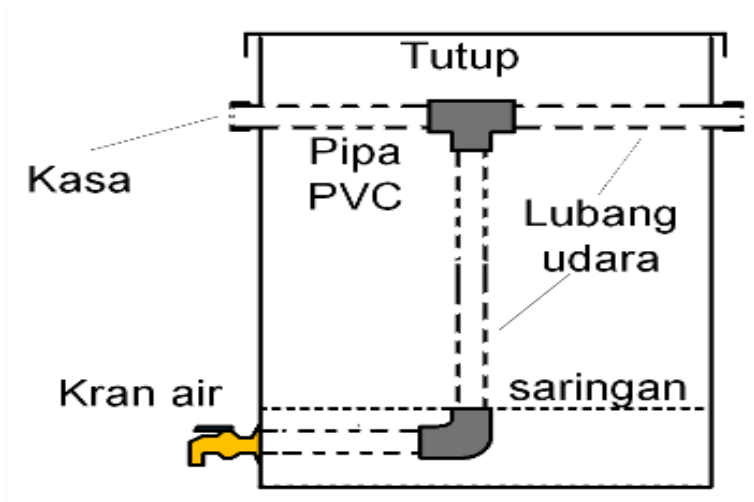

Gambar 4. Komponen Tong Komposter

\section{Molase}

Molase merupakan cairan yang berasal dari sari tetes tebu atau biang gula. Molase dapat dibuat secara manual dengan cara melarutkan gula putih atau gula merah ke dalam air bersih dengan perbandingan 1:1.

\section{Bahan:}

a. Gula putih/gula merah.

b. Air.
Alat:
a. Panci.
b. Pegaduk.

\section{Cara Pembuatan:}

a. Siapkan air bersih dalam panci.

b. Dengan perbandingan 1:1 masukkan gula merah/gula putih dalam panci.

c. Aduk gula merah/gula putih sampai larut.

d. Setelah jadi maka larutan ini dapat dijadikan sebagai biang untuk pembuatan pupuk kompos cair. 


\section{Efektif Mikroorganisme}

Efektif mikroorganisme merupakan bahan yang memiliki fungsi untuk mempercepat proses pengkomposan dengan cara penambahan bakteri.

\section{Bahan:}

a. Susu sapi/kambing murni.

b. Usus ayam/kambing secukupnya.

c. Terasi $1 / 2 \mathrm{~kg}$.

d. $1 \mathrm{~kg}$ gula pasir (perasan tebu).

e. $1 \mathrm{~kg}$ bekatul.

f. 1 buah nanas.

g. 10 liter air.
Alat:
a. Panci.
b. Kompor.
c. Blender atau parutan.

\section{Cara Pembuatan:}

a. Nanas dihaluskan dengan blender.

b. Nanas yang sudah dihaluskan dimasukkan ke dalam panci.

c. Terasi, bekatul, gula pasir dan air bersih dimasukkan panci bersama dengan nanas.

d. Masak hingga mendidih.

e. Tambahkan susu dan usus aduk hingga merata.

f. Setelah merata tutup rapat-rapat selama 12 jam.

g. Jika sudah jadi maka akan menghasilkan cairan yang kental atau lengket dan dianggap berhasil apabila terdapat gelembung-gelembung di permukaan. 
Pada pelatihan kali ini menggunakan efektif mikroorganisme yang sudah ada dipasaran yaitu EM4.

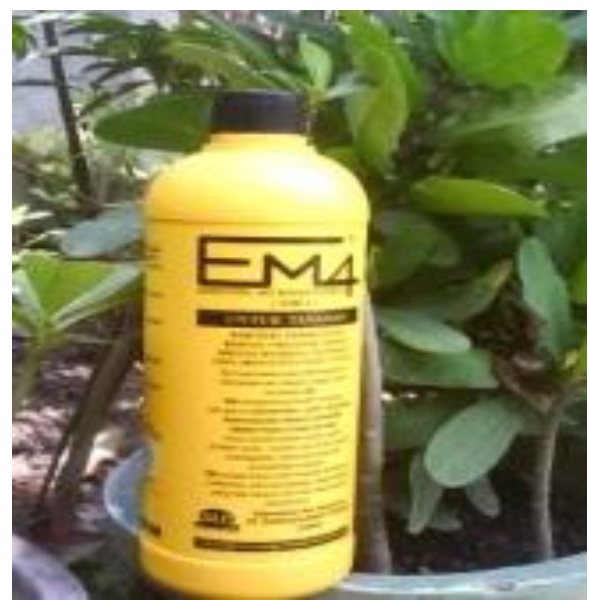

Gambar 5. EM4

\section{Pembiakan EM}

Cairan bakteri EM dapat dikembangbiakkan dengan cara sebagai berikut:

\section{Bahan:}

a. Cairan EM 1 liter.

b. Bekatul $3 \mathrm{~kg}$.

c. Molase $1 / 4$ liter.

d. Terasi $1 / 4 \mathrm{~kg}$.

e. Air bersih 5 liter.

\section{Alat:}
a. Ember.
b. Pengaduk kayu.
c. Panci pemasak air.
d. Saringan (kain/kawat kasa).
e. Botol. 


\section{Cara Pembuatan:}

a. Panaskan 5 liter air sampai mendidih.

b. Bekatul, molase dan terasi dimasukkan dan diaduk hingga rata.

c. Setelah menjadi adonan kemudian dinginkan.

d. Masukkan cairan EM dan aduk secara merata.

e. Panci ditutup rapat-rapat selama dua hari.

f. Pada hari ketiga dan selanjutnya penutup dibuat agak longgar dan dilakukan pengadukan sekitar sepuluh menit.

g. Setelah tujuh hari bakteri disaring dan dimasukkan ke dalam botol.

h. Untuk penyimpanannya simpan di tempat yang sejuk dan jauh dari sinar matahari secara langsung.

\section{B. Pembuatan Pupuk Organik Cair}

\section{Pupuk Organik Cair Sederhana}

\section{Bahan:}

a. Sampah organik daun kering.

b. Molase $1 / 2$ liter.

c. Air bekas cucian beras 1 liter.

d. Air bersih 1 liter.
Alat:
a. Karung beras.
b. Gayung.
c. Ember.

\section{Cara Pembuatan:}

a. Sampah organik daun kering yang dikumpulkan masukkan ke dalam karung dan padatkan.

b. Kemudian ikat karung rapat-rapat bagian atasnya.

c. Membuat larutan organik dengan mencampurkan molase, air bekas cucian beras dan air ke dalam ember.

d. Setelah semua bahan tercampur dengan rata, sampah organik yang berada dalam karung dimasukkan ke dalam ember dan pastikan karung tidak mengambang. 
e. Tutup ember rapat-rapat selama tujuh sampai sepuluh hari di tempat yang teduh dan tidak terkena matahari secara langsung.

f. Setelah fermentasi selesai buka ember.

g. Fermentasi yang berhasil ditandai dengan adanya bercak putih pada permukaan cairan, warna cairan kecoklatan dan memiliki bau dan aroma yang menyengat.

\section{Pupuk Organik Cair Dengan EM}

\section{Bahan:}

a. Sampah organik daun kering.

b. EM4.

c. Molase.

d. Air.
Alat:
a. Tong komposter.
b. Pengaduk.
c. Botol.
d. Ember.

\section{Cara Pembuatan:}

a. Campurkan EM4, molase dan air dalam ember lalu aduk merata.

b. Setelah merata tuang ke dalam botol tutup rapat sampai kurang lebih tiga hari menjadi cairan mikroba dekomposer.

c. Sampah organik daun kering dipotong menjadi ukuran lebih kecil terlebih dahulu agar proses dekomposisinya lebih cepat dan sempurna. Selain itu potongan yang kecil-kecil bisa memaksimalkan kapasitas atau daya tampung komposter.

d. Masukkan cacahan daun dan mikroba dekomposer ke dalam tong komposter lalu tutup rapat-rapat tong komposter. 
e. Pemakaian komposter baru bisa menghasilkan air lindi atau pupuk organik cair dalam waktu dua minggu.

f. Selanjutnya hasil pupuk organik cair yang dihasilkan dapat digunakan dan diambil sesuai dengan kebutuhan melalui kran air pada tong komposter.

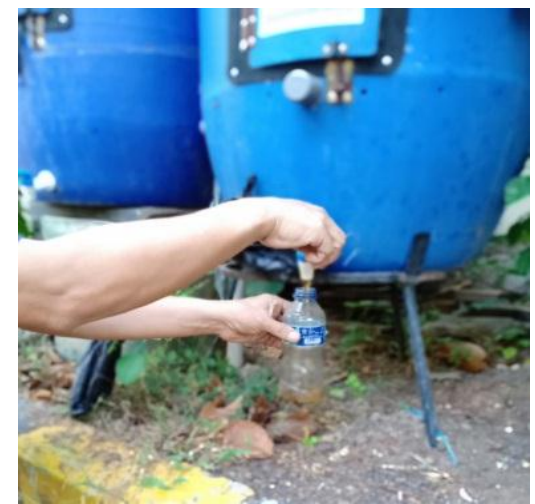

Gambar 6. Pupuk Organik Cair

g. Selain air lindi yang dihasilkan, sampah daun kering yang terdapat dalam komposter juga dapat dimanfaatkan sebagai pupuk organik padat.

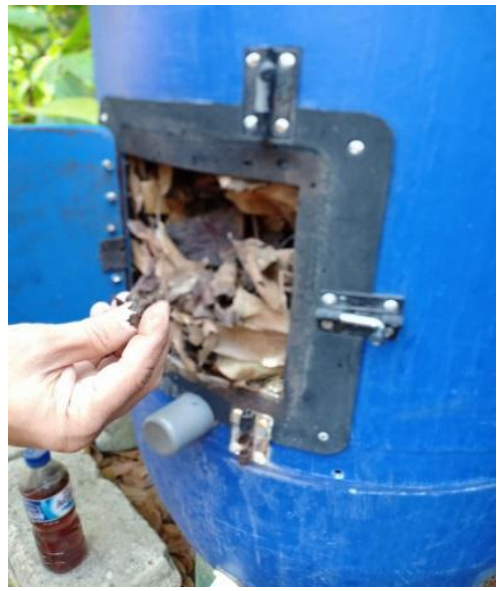

Gambar 7. Pupuk Organik Padat 


\section{Latihan/Praktek:}

1. Peserta diminta untuk membuat pupuk organik cair dengan bahan yang telah disiapkan dan dalam pengerjaannya di dampingi oleh instruktur.

2. Peserta diminta menyerahkan hasil pembuatan pupuk organik cair yang dihasilkan. 